\title{
Synthesis, Characterization and Antimicrobial Evaluation of Schiff Bases of 4-Amino-5-(4-Tert-butylphenyl)-4H-1,2,4- Triazole-3-Thiol
}

\author{
Kamal Prasad Kapri and Bhushan Shakya* \\ Department of Chemistry, Amrit Campus, Tribhuvan University, \\ Kathmandu, Nepal \\ E-mail: bhusansakya@gmail.com
}

\begin{abstract}
Triazoles are the five membered heterocyclic compounds having aromatic ring similar to that of pyrazole and imidazole but with an additional nitrogen atom in ring structure. Triazoles possess broad spectrum of biological activities which include antimicrobial, antifungal, antibacterial, antitubercular, anticancer, anti-oxidant, anti-inflammatory, antiviral and anticonvulsant activities. 1,2,4-triazole derivatives have received much attention due to their versatile biological properties as well as wideranging agrochemical and chemical properties. Hence, efforts have been made to synthesize 4-amino-5(4-tert-butylphenyl)-4H-1,2,4-triazole-3-thiol and its Schiff bases using p-tert-butylbenzoic acid as precursor. The structures of newly synthesized compounds (5a and $\mathbf{5 b})$ were confirmed by IR, ${ }^{l} H-N M R$ and ${ }^{13} C$-NMR spectral analyses. These compounds were evaluated for their antimicrobial activity against bacterial strains - S. aureus, E. coli and S. typhi as well as the fungal strain, C. albicans. The results reveal that $\mathbf{5} \boldsymbol{a}$ and $\mathbf{5 b}$ displayed moderate activities against the tested microorganisms.

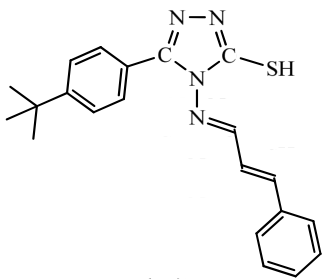

(5a)

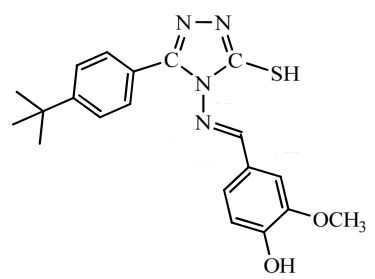

(5b)

Keywords: 1,2,4-triazole, Schiff base, Thiol derivatives, Synthesis, Antimicrobial activities

\section{Introduction}

Heterocyclic chemistry is the most challenging and more adequately rewarding field of organic chemistry with long history and future prospects ${ }^{1}$. The heterocyclic compounds containing nitrogen, oxygen and sulphur in the ring positions have significant interest in agrochemical ${ }^{2}$ and medicinal chemistry due to their wide ranging biological targets ${ }^{3}$. Among heterocyclic compounds, the nitrogen containing heterocycles are one of the key intermediate and these are abundantly found in most of the medicinal compounds ${ }^{4}$.
\end{abstract}

\footnotetext{
* Corresponding author
} 


\section{J. Nepal Chem. Soc., Vol. 39, 2018}

Triazoles are the five membered aromatic heterocyclic compounds containing similar ring to that of azole, pyrazole and imidazole but with an additional nitrogen atom in the ring structure. Triazoles are said to be the isosters of imidazole, which is a part of the azole group of antifungal drugs such as Fluconazole, Itraconazole, Voriconazole, Ravuconazole and Posaconazole ${ }^{5}$.Triazole and its derivatives represent one of the most biologically active classes of organic compounds that have received a great deal of attention since their discovery ${ }^{6}$. 1,2.4-triazole nucleus, being an important pharmacophore has a wide range of pharmacological properties such as anticancer ${ }^{7-10}$, antifungal ${ }^{11,12}$ antiviral $^{13-15}$, anti-inflammatory ${ }^{16-18}$, anticonvulsant $^{19,20}$, antimalarial ${ }^{21}$, antitubercular ${ }^{22}$, antidepressant ${ }^{23}$, antihypertensive ${ }^{24,25}$, analgesic ${ }^{26-28}$, and antioxidant ${ }^{17,29}$ activities. In recent years, the synthesis of novel heterocycles from 1,2,4-triazole moiety has been attracting increasing interest for heterocyclic chemists due to their synthetic and effective medicinal importance. 1,2,4-Triazole ring has been incorporated into a wide variety of interesting drugs including $\mathrm{H} 1 / \mathrm{H} 2$ histamine receptor blockers, CNS stimulants, anti-anxiety agents, and sedatives ${ }^{30}$, some of these are Alprazolam ${ }^{31}$, Furacyclin ${ }^{32}$, Etizolam $^{33}$, Ribavirin ${ }^{34}$ and Triazolam ${ }^{35}$.

Schiff basses are the compounds containing azomethine functional group $(-\mathrm{C}=\mathrm{N}-)$ that are typically formed by condensation of a primary amine and an aromatic aldehyde. Schiff bases have gained importance in medicinal and pharmaceutical fields due to their structural similarities with natural biological substances and relatively simple, flexible synthetic procedures that enable to design compounds with suitable structural properties ${ }^{36-38}$.

In present work we have synthesized 1,2,4-triazole-3-thiols incorporating 4-tert-butylphenyl moiety and its Schiff bases with vanillin and cinnamaldehyde.

\section{Experimental Methods}

The progress of reaction was monitored by TLC using silica gel coated aluminum plates and spots were visualized in iodine chamber. Melting point was determined on Optics Technology electro-thermal apparatus by open capillary tube and are uncorrected; IR spectra were recorded on BRUKER 375-FTIR spectrometer. ${ }^{1} \mathrm{H}-\mathrm{NMR}$ and ${ }^{13} \mathrm{C}-\mathrm{NMR}$ spectra were obtained from BRUKER Bio spin Advance III 400 MHz FT-NMR spectrometer using DMSO- $d_{6}$ as the solvent with TMS as internal standard. Chemical shifts are reported in parts per million (ppm) and signals are described as singlet $(s)$, doublet $(d)$, triplet $(t)$ and multiplet $(m)$.

\section{Synthesis}

The syntheses of the compounds were carried out as illustrated in Scheme 1.

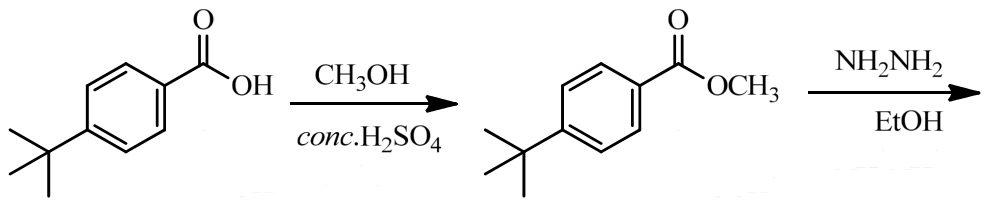

(1)<smiles>CC(C)(C)c1ccc(C(=O)NN)cc1</smiles>

(2) 


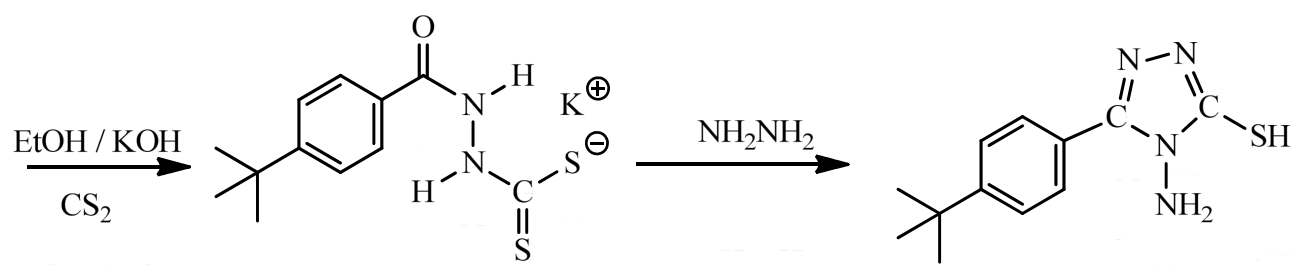

(3)

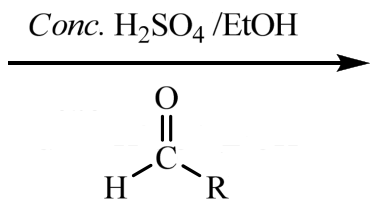

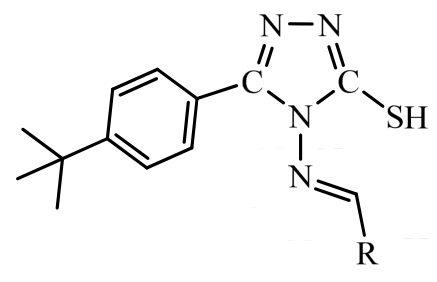

(5)
(4)<smiles>C/C=C/c1ccccc1</smiles>

(5b)

Scheme.1: Synthesis of Schiff base

\section{Synthesis of methyl-4-tert-butylbenzoate (1)}

A mixture of 4-tert-buytylbenzoic acid $(17.82 \mathrm{~g}, 0.1 \mathrm{~mol})$, anhydrous methanol $(22 \mathrm{~mL})$ and conc. sulphuric acid $(1 \mathrm{~mL})$ was refluxed for $5 \mathrm{~h}$. The volume of solution was reduced to half by evaporating. After cooling it was diluted with $50 \mathrm{~mL}$ water and the ester was extracted with anhydrous diethyl ether. It was then washed with $20 \%(\mathrm{w} / \mathrm{v})$ solution of sodium bicarbonate and then dried over anhydrous magnesium sulphate.

Yield 78\%, (14.976 g), Colourless liquid.

\section{Synthesis of 4-tert-butylbenzohydrazide (2)}

$99 \%$ hydrazine hydrate $(0.750 \mathrm{~g}, 0.015 \mathrm{~mol})$ was added drop wise, with constant stirring, to a solution of $1(1.92 \mathrm{~g}, 0.01 \mathrm{~mol})$ in absolute ethanol $(20 \mathrm{~mL})$ and refluxed for $6 \mathrm{~h}$. The solution was then concentrated and cooled. The solid mass separated out was washed with ethanol, dried and recrystallized from ethanol.

Yield $64 \%$, (1.612 g), yellowish white, rhombus shaped crystal, m.p. $120^{\circ} \mathrm{C}$.

\section{Synthesis of potassium 2-(4-tert-butylbenzoyl) hydrazinecarbodithioate (3)}

Carbon disulphide $(1.14 \mathrm{~g})$ was added drop wise to ice cold mixture of potassium hydroxide $(0.84 \mathrm{~g}$, $0.015 \mathrm{~mol})$, ethanol $(20 \mathrm{~mL})$ and acid hydrazide $(1.92 \mathrm{~g}, 0.01 \mathrm{~mol})$ and then refluxed for $16 \mathrm{~h}$. Anhydrous diethyl ether $(20 \mathrm{~mL})$ was added and the solid separated out was washed several times with diethyl ether and recrystallized with ethanol.

Yield $60 \%,\left(2.754\right.$ g), white shining, needle shaped crystal, m.p. $310^{\circ} \mathrm{C}$ 


\section{Synthesis of 4-amino-5-(4-tert-butylphenyl)-4H-1,2,4-triazole-3-thiol (4)}

A suspension of potassium dithiocarbazinate $(3.06 \mathrm{~g}, 0.01 \mathrm{~mol})$ in water $(10 \mathrm{~mL})$ and hydrazine hydrate $(1$ $\mathrm{g}, 0.02$ mole) was refluxed till the evolution of hydrogen sulphide gas was ceased. The reaction mixture was cooled, diluted with water $(100 \mathrm{~mL})$ containing some crushed ice and acidified with dil. hydrochloric acid. The solid mass separated was filtered, washed with cold water and recrystallized with ethanol.

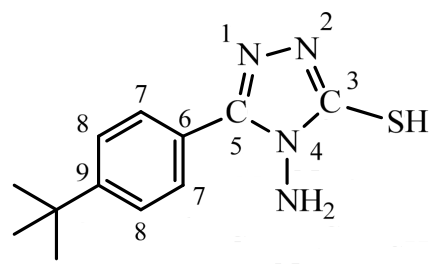

Yield 65\%, (1.612 g, $0.0065 \mathrm{~mol})$, light yellow, amorphous solid, m.p. $156{ }^{\circ} \mathrm{C}, \mathrm{IR}\left(\mathrm{KBr}, v \mathrm{~cm}^{-1)}: 3220(\mathrm{~m})\right.$, 3199(m), 3109(m), 2950(s), 2849(s), 2589(w), 1655(m), 1521(s), 1437(s), 1161(s), 684(s); ${ }^{1} \mathrm{H}$ NMR $\left(400 \mathrm{MHz}, \mathrm{DMSO}-d_{6}\right) \delta=13.92$ (1H, br. s., HS-), $7.78(2 \mathrm{H}, \mathrm{d}, J=5.9 \mathrm{~Hz}, \mathrm{H}-7), 7.58$ (2H, d, $J=6.1 \mathrm{~Hz}$, H-8), 1.28 (9H, br. s., $\left.\mathrm{CH}_{3}\right){ }^{13} \mathrm{C}$ NMR (100MHz, DMSO- $\left.d_{6}\right) \delta=177.7$ (C-3), 161.0 (C-9), 155.7 (C-5), 126.7 (C-6), 126.4 (C-7), 120.2 (C-8), 35.3(t-Bu C) $), 31.4\left(\underline{\mathrm{CH}}_{3}\right)$

\section{Synthesis of Schiff base (5)}

To the hot ethanolic solution of aromatic aldehyde containing 4-5 drops of conc. sulphuric acid, a hot ethanolic solution of $\mathbf{4}$ was added and refluxed for $5 \mathrm{~h}$. The solid formed was filtered, washed with cold ethanol and recrystallized from ethanol.

\section{Synthesis of 5-(4-(tert-butylphenyl)-4-(3-phenylallylideneamino)-4H-1,2,4-triazole-3-thiol (5a)}

To a solution of triazole $(0.496 \mathrm{~g}, 0.002 \mathrm{~mol})$ in anhydrous ethanol $(5 \mathrm{~mL})$, cinnamaldehyde $(0.264 \mathrm{~g}$, $0.002 \mathrm{~mol})$, was added with constant stirring. After adding conc. sulphuric acid $(5 \mathrm{~mL})$, the mixture was refluxed for $5 \mathrm{~h}$ and cooled. The solid separated was filtered, washed with cold ethanol and recrystallized with ethanol.

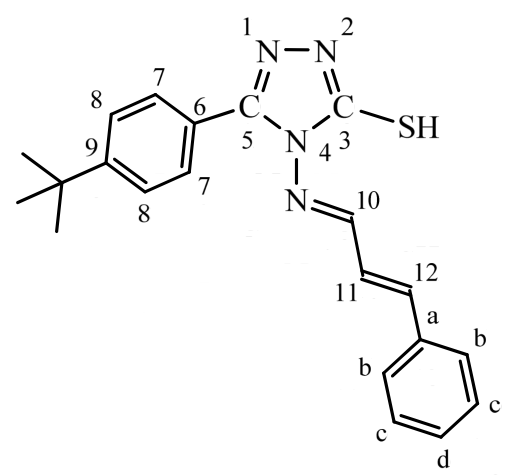

Yield 63\%, (0.456 g, $0.00126 \mathrm{~mol})$ pale yellow, amorphous solid, m.p. $182-184{ }^{\circ} \mathrm{C}, \mathrm{IR}\left(\mathrm{KBr}, v \mathrm{~cm}^{-1}\right)$ : 3120(m), 3011(m), 2952(m), 2576(w), 1650(m), 1583(m), 1512(s), 1437(s), 1121(s), 675(s); ${ }^{1} \mathrm{H}$ NMR (400 MHz, DMSO-d $) \delta=14.07$ (1H, br. s., HS-), 9.34 (1H, d, $J=9.5 \mathrm{~Hz}, \mathrm{H}-10), 7.96$ (2H, d, J= 8.8 Hz, 
H-7), 7.55 - 7.80 (2H, m, H-b), 7.23 - 7.48 (6H, m, H-c, H-8, H-d, H-12), 7.13 (1H, dd, $J=16.1 \mathrm{~Hz}, J=$ $9.5 \mathrm{~Hz}, \mathrm{H}-11), 1.37$ (9H, br. s., $\left.\mathrm{C}_{3}\right) ;{ }^{13} \mathrm{C}$ NMR $\left(100 \mathrm{MHz}, \mathrm{DMSO}-d_{6}\right) \delta=168.3$ (C-3), $162.2(\mathrm{C}-10)$, 149.9 (C-9), 148.7 (C-5), 147.0 (C-a), 135.4 (C-12), 130.7 (C-c), 129.4 (C-b), 129.0 (C-d), 128.5 (C-6), 126.1 (C-8), 125.8 (c-7), 119.4 (C-11), 34.3 (t-Bu C $), 31.4\left(\underline{\mathrm{CH}}_{3}\right)$

Synthesis of 5-(4-tert-butylphenyl)-4-(4-hydroxy-3-methoxybenzylidene- amino)-4H-1,2,4-triazole-3thiol (5b)

To a solution of triazole $(0.496 \mathrm{~g}, 0.002 \mathrm{~mol})$ in anhydrous ethanol $(5 \mathrm{~mL})$, vanillin $(0.304 \mathrm{~g}, 0.002$ mol) was added with constant stirring. After adding conc. sulphuric acid $(5 \mathrm{~mL})$ the mixture was refluxed for $5 \mathrm{~h}$ and cooled. Thus formed solid was filtered, washed with cold ethanol and recrystallized with ethanol.

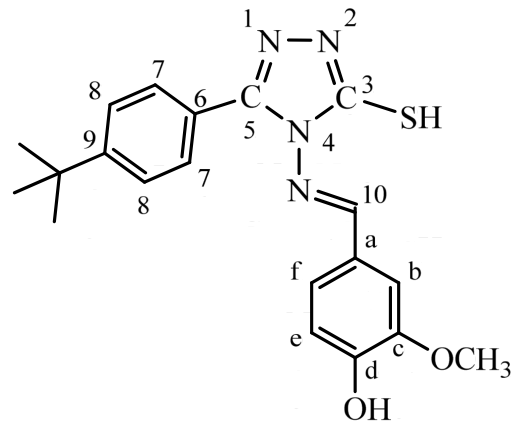

Yield 67\%, (0.511 g, $0.00134 \mathrm{~mol})$ light green, amorphous solid, m.p. 196-198 ${ }^{\circ} \mathrm{C}$, IR $\left(\mathrm{KBr}, v \mathrm{~cm}^{-1}\right)$ : 3340(s), 2962(m), 2896(m), 2550(w), 1655(s), 1614(s), 1594(m), 1502(s), 1313(m), 1114(s), 676(s); ${ }^{1} \mathrm{H}$ NMR (400MHz, DMSO- $\left.d_{6}\right) \delta=14.04$ (1H, br. s., HS-), 10.05 (1H, br. s., HO-), 9.98 (1H, br. s., H-10), $7.96(2 \mathrm{H}, \mathrm{d}, J=8.8 \mathrm{~Hz}, \mathrm{H}-7), 7.30$ - 7.55 (3H, m, H-b \& H-8), $7.15-7.30$ (1H, m, H-f), 6.81 - 7.06 (1H, m, H-e), 3.77 (3H, br. s., $\left.\mathrm{CH}_{3} \mathrm{O}-\right), 1.37$ (9H, br. s., $\left.\mathrm{CH}_{3}\right) ;{ }^{13} \mathrm{C}$ NMR $\left(101 \mathrm{MHz}, \mathrm{DMSO}-d_{6}\right) \delta=167.1(\mathrm{C}-3)$, 162.3 (C-10), 151.8 (C-9), 149.9 (C-5), 148.6 (C-d), 148.5 (C-c), 129.1(C-6), 126.1 (C-a), 125.9 (C-8), 124.6 (C-7), 123.9 (C-f), 116.1 (C-e), 111.3 (C-b), $56.1\left(\underline{C H}_{3} \mathrm{O}\right), 34.3(t-\mathrm{Bu} \underline{\mathrm{C}}), 31.4\left(\underline{\mathrm{CH}}_{3}\right)$

\section{Antimicrobial activity}

The solution of newly synthesized compounds $\mathbf{5 a}$ and $\mathbf{5 b}$ prepared in DMSO were screened at a concentration of $3 \mathrm{mg} \cdot \mathrm{mL}^{-1}$ for their antimicrobial activity against three bacterial species [one Gram positive, Staphylococcus aureus (ATCC: 25923) and two Gram negative, Escherichia coli (ATCC: 25922), Salmonella typhi] and one species of yeast, Candida albicans by well-diffusion method. The overnight culture of bacteria from nutrient agar medium and 48 hour culture of yeast from potato dextrose agar were inoculated in Muller-Hinton broth and incubated for $3-4 \mathrm{~h}$ at $37^{\circ} \mathrm{C}$ till the turbidity matched with McFarland Standard 0.5. After standardization of the suspension, a sterile cotton swab was immersed in it and excess of suspension was pressed along the side of the tube. A lawn culture of organism was made on Mueller Hinton agar. Wells were made on these seeded agar plates by using a sterile metallic borer and the prepared solution $(50 \mu \mathrm{L})$ of the test compounds and control (Ofloxacin, 3 $\left.\mathrm{mg} \cdot \mathrm{mL}^{-1}\right)$ were loaded into each labeled well with the help of sterile micropipette. The Petri dishes were 


\section{J. Nepal Chem. Soc., Vol. 39, 2018}

incubated at $37{ }^{\circ} \mathrm{C}$ for $24 \mathrm{~h}$ and antimicrobial activity was determined by measuring the diameter of inhibition zone of each compound and compared with Ofloxacin as standard.

\section{Results and Discussion}

4-amino-5-(4-tert-butylphenyl)-4H-1,2,4-triazole-3-thiol (4) was synthesized by cyclization of potassium 2-(4-tert-butylbenzoyl) hydrazinecarbodithioate with hydrazine hydrate. Condensation of 4 with the aldehydes gave the Schiff bases 5-(4-(tert-butylphenyl)-4-(3-phenylallylideneamino)-4H-1,2,4triazole-3-thiol (5a) and 5-(4-tert-butylphenyl)-4-(4-hydroxy-3-methoxybenzylidene- amino)-4H-1,2,4triazole-3-thiol (5b). The structures of the newly synthesized compounds were confirmed by IR, ${ }^{1} \mathrm{H}$ and ${ }^{13} \mathrm{C}-\mathrm{NMR}$ spectroscopy

\section{IR Spectra}

The IR spectral analysis supports the presence of characteristic groups in the synthesized compounds. A couple of bands with medium absorption due to stretching vibrations of $\mathrm{NH}_{2}$ are observed at the region 3220 and $3199 \mathrm{~cm}^{-1}$ in the spectra of compound 4 . The disappearance of these bands in the spectra of $5 \mathbf{a}$ and $\mathbf{5 b}$ confirmed the formation of Schiff bases. The medium absorption at $3120-3109 \mathrm{~cm}^{-1}$ and strong absorptions at $3011-2849 \mathrm{~cm}^{-1}$ are attributable to $(\mathrm{C}=\mathrm{CH})$ and $(\mathrm{C}-\mathrm{H})$ respectively. The strong absorptions in the region $1650 \mathrm{~cm}^{-1}-1437 \mathrm{~cm}^{-1}$ are due to the stretching vibrations of azomethine $(\mathrm{C}=\mathrm{N})$ and ring breathing $(\mathrm{C}=\mathrm{C})$. Although triazole thiols can exist in thione-thiol tautomeric forms, the presence of weak absorption in the region $2589 \mathrm{~cm}^{-1}-2550 \mathrm{~cm}^{-1}$ corresponding to stretching vibration of S-H suggest that synthesized compounds exist in thiol form in the solid state. The strong intensity band at $1161-1114 \mathrm{~cm}^{-1}$ and $684-675 \mathrm{~cm}^{-1}$ are characteristic of N-N and Ar-H respectively. In addition, in the spectra of 5a strong absorption at $3340 \mathrm{~cm}^{-1}$ and medium absorption at $1313 \mathrm{~cm}^{-1}$ also exist due to stretching and bending respectively of $\mathrm{Ar}-\mathrm{OH}$.

\section{${ }^{1}$ H-NMR Spectra}

The ${ }^{1} \mathrm{H}-\mathrm{NMR}$ spectra of synthesized compounds are consistent with the analogous triazole thiol Schiff bases. The ${ }^{1} \mathrm{H}-\mathrm{NMR}$ spectra of the compounds display broad singlet at 13.92-14.07 ppm corresponding to the thiol proton $(-\mathrm{SH})$ which is much deshielded due to adjacent strongly electron withdrawing triazole nucleus. The signals due to the protons of aromatic ring appear at $7.96-7.23 \mathrm{ppm}$. The low frequency broad singlet in the aliphatic regions is observed at $1.28-1.37 \mathrm{ppm}$ for the $t$-butyl protons. The formation of Schiff bases is also confirmed by absence of $\mathrm{N}-\mathrm{H}$ band in IR spectra and the presence of signal due to imine proton $(-\mathrm{N}=\mathrm{CH}-)$ at 9.34 and $9.98 \mathrm{ppm}$ in ${ }^{1} \mathrm{H}$ NMR of $\mathbf{5 a}$ and $\mathbf{5 b}$ respectively. A doublet in spectra of $5 \mathbf{a}$ at $9.34 \mathrm{ppm}$ with $J$ value of $9.5 \mathrm{HZ}$ is attributed to imine proton while a doublet of doublet with $J$ values at 16.1 and $9.5 \mathrm{ppm}$ is due to the proton on the carbon adjacent to this. Whereas, in the spectra of 5b there are additional signals at $10.05 \mathrm{ppm}$ and $3.77 \mathrm{ppm}$ due to the $-\mathrm{OH}$ and $-\mathrm{OCH}_{3}$ protons.

\section{${ }^{13}$ C-NMR Spectral analysis}

The appearance of a peaks at $\delta=167.1-177.7 \mathrm{ppm}$ indicate the $\mathrm{C}-\mathrm{SH}$ and $\mathrm{C}=\mathrm{N}$ carbons of triazole nucleus. The peak at $149.9-161.0$ is attributed to the aromatic carbon adjacent to the tert-butyl group. The peak for other aromatic carbons appear in the region $120.2-148.6 \mathrm{ppm}$. The signals in the aliphatic region i.e. at $34.3-35.3$ and 31.4 correspond to the carbons of $t$-butyl group. The signal at $56.1 \mathrm{ppm}$ in the spectra of $\mathbf{5 b}$ was attributable to the methoxy carbon. 


\section{Antimicrobial evaluation}

The antimicrobial activity of Schiff bases $\mathbf{5 a}$ and $\mathbf{5 b}$ were examined against all tested microorganisms at a concentration of $3 \mathrm{mg} \cdot \mathrm{mL}^{-1}$ using Ofloxacin as standard and the results are summarized in table 1 . Among these 5a exhibited strong biological activity against $S$. aureus more than other Gram negatives. The compound $\mathbf{5 b}$ displayed better activity against $S$. typhi, while showed moderate activity against $S$. aureus and E. coli. The Schiff bases $\mathbf{5 a}$ and $\mathbf{5 b}$ exhibited significant antifungal activity towards Candida albicans (yeast).

Table 1: Antimicrobial activities of Schiff bases

\begin{tabular}{|c|c|c|c|c|}
\hline \multirow{3}{*}{$\begin{array}{l}\text { Compound } \\
\text { Code }\end{array}$} & \multicolumn{4}{|c|}{ Diameter of Zone of Inhibition (mm) } \\
\hline & \multicolumn{3}{|c|}{ Bacterial Strains } & Fungal strain \\
\hline & S. aureus & E. coli & S. Typhi & C. albicans \\
\hline $5 \mathrm{a}$ & 29.5 & 18.5 & 20 & 15 \\
\hline $5 b$ & 26 & 23 & 28 & 18 \\
\hline Ofloxacin & 40 & 39 & 38 & 22 \\
\hline
\end{tabular}

\section{Conclusions}

The Schiff bases (5a and $\mathbf{5 b}$ ) were successfully synthesized which are thermally stable and soluble in DMSO. The bonding of $\mathrm{N}$-atom of amino group of thiol (4) with the carbonyl carbon of aromatic aldehydes as a result of condensation leading to the formation of Schiff bases were confirmed by analytical methods such as IR, ${ }^{1} \mathrm{H}-\mathrm{NMR}$ and ${ }^{13} \mathrm{C}-\mathrm{NMR}$ spectroscopy. The spectroscopic evidence supports the proposed structures of synthesized compounds. The antimicrobial screening suggests that, the synthesized compounds exhibited moderate activities against all the tested microorganisms. 5a exhibited stronger biological activity against $S$. aureus than Gram negatives, while it is reverse in case of 5b. Further modification of this class of compounds may lead to safer antimicrobial agents.

\section{Acknowledgements}

We are thankful to Dr. Sabita Shrestha (Central Department of Chemistry, TU) for the IR measurements, Deval Prasad Bhattarai and Dr. Ek Raj Baral (Chonbuk National University, South Korea) for the NMR data acquisition, and Santosh Khanal (Department of Microbiology, National College) for antimicrobial evaluation.

\section{References}

1. R. Haddad and E.A. Yousif, Springer plus, 2013, 2, 510.

2. P.K. Shukla, N. Soni,; A. Verma, and A.K. Jha, Der Pharma Chemica, 2014, 6, 153.

3. G.M. Malik and S.K. Zadafiya, Der Chemica Sinica, 2010, 1, 15.

4. H.P. Michael, J.C. Philip, V.H. Soren, C.J. Nykola, R.H. Ashley and L.L. Dennis, J. Chem. Phys., 2012, 136, 094310.

5. S. Castellano, G. Stefancich, A. Chillotti and G. Poni, Il Farmaco, 2003, 58, 563.

6. H.L. Yale and K. Losee, J. Med. Chem., 1966, 9, 478. 


\section{J. Nepal Chem. Soc., Vol. 39, 2018}

7. S. Yan, Y. Liu, Y. Chen, L. Liu and J. Lin, Bioorg. Med. Chem. Lett., 2010, 20, 5225.

8. S.B. Holla, B. Veerendra and M.K. Shivananda, Eur. J. Med. Chem., 2003, 38, 759.

9. N. Demirbas, R. Ugurluoglu and A. Demirbas, Bioorg. Med. Chem., 2002, 10, 3717.

10. I.B. Sayeed, M.V.P.S. Vishnuvardhan, A. Nagarajan, S. Kantevari and A. Kamal, Bioorg. Chem. 2018, 80, 714

11. N. Ergenc, E. Iihan and G. Otuk, Pharmazie, 1992, 47, 59.

12. P. Yadav, K. Lal, L. Kumar, A. Kumar, A. Kumar, A.K. Paul and R. Kumar, 2018, 155, 263.

13. B.E. Gilbert and V. Knight, Antimicrob. Agents Chemother., 1986, 30, 201.

14. O.G. Todoulou, A.E. Papadaki-Valiraki and S. Ikeda, Eur. J. Med. Chem., 1994, 29, 611.

15. S. Abel and D.J. Back, Antivir. Therapy, 2009, 14, 607.

16. H. Muhammad, S. Muhammad, T.H. Muhammad, H.R. Nasim, Z. Sumera, A.M. Muhammad, P.G.J. Aslam and I. Jamshed, J. Braz. Chem. Soc., 2012, 23, 854.

17. S. Maddila, S. Gorle, M. Singh, P. Lavanya and S.B. Jonnalagadda, Lett. Drug Design Dis., 2013, 10, 977.

18. C. Travelli, S. Aprile, R. Rahimian, A.A. Grolla, F. Rogati, M. Bertolotti, F. Malagnino, R. di Paola, D. Impellizzeri, R. Fusco, V. Mercalli, A. Massarotti, G. Stortini, S. Terrazzino, E. Del Grosso, G. Fakhfouri, M.P. Troiani, M.A. Alisi, G. Grosa, G. Sorba, P.L. Canonico, G. Orsomando, S. Cuzzocrea, A. A. Genazzani, U. Galli, and G.C. Tron J. Med. Chem., 2017, 60, 1768.

19. I. Kucukguzel, S.G. Kucukguzel, S. Rollas, G. Otuk-sanis, O. Ozdemir, I. Bayrak, T. Altug and J.P. Stables, Farmaco, 2004, 59, 893.

20. M. Mahdavi, T. Akbarzadeh, V. Sheibani, M. Abbasi, L. Firoozpour, S.A. Tabatabai, A. Shafiee and A. Foroumadi, Iranian J. Pharma Res. 2010, 9, 265.

21. R.C. Corrales, N.B. de Souza, L.S. Pinheiro, C. Abramo, E.S. Coimbra and A.D. Da Silva, Biomed. Pharmacother., 2011, 65 (3), 198.

22. R. M. Mali, R.R. Somain, M.P. Toraskar, K.K. Mali, P.P. Naik, P.Y. Shirodkar, Int. J. Chem. Tech. Res., 2009, 1, 168.

23. F.B.G. Stefania, C.D. Gabriela, and B.G.B. Florica, Eur. J. Med. Chem., 2012, 49, 417.

24. H. Emilsson and H. Selander, Acta Pharm. Suec., 1983, 20, 419.

25. K. A. Ali, E.A. Raqab, T.A. Farghaly and M.M. Abdalla, Acta Pol. Pharm. 2011, 68, 237.

26. M.J. Kane, M.W. Dubley, M.S. Sorensen and F.P. Miller J. Med. Chem., 1988, 31, 1253.

27. G. Turan-Zitouni, Z. A. Kapalancikli, K. Erol and F.S. Kilic, Farmaco, 1999, 54, 218.

28. P.K. Goyal, A. Bhandari, A.C. Rana and C.B. Jain, Intl. J. Chem. Tech. Res. 2010, $2,1992$.

29. H. Kumar, A.S. Javed, A.S. Khan and M. Amir, Eur. J. Med Chem., 2008, 43, 2688.

30. M. Whiting, J. C. Tripp, Y.C. Lin, W. Lindstrom, A.J. Olson, J. H. Elder, K.B. Sharpless and V.V. Fokin, J. Med. Chem., 2006, 4, 7697.

31. D.L. Coffen, R.I. Fryer, U.S. Pat. 3,849, 434, 1974; Chem. Abstr. 1973, 82730044v.

32. F.D. Povelista, A.G. Gural, Antibiotiki (Moscow) 1973, 18, 71; Chem. Abstr. 1973, 78, 93044. 
33. M. Shiroki, Y. Tahara and K. Araki, Jap. Pat. 75100096, 1975.

34. R.W. Sidwell, L.B. Allen, J.H. Hoffman, J.T. Witkowsti and L.N. Simon, Proc. Soc. Exp. Biol. Med., 1975, 148, 854.

35. A. Brucato, A. Copoola, S. Gianguzza, P.M. Provenzano, Bull. Soc. Ital. Sper., 1978, 54, 1051.

36. E. Jungreis and S. Thabet, Analytical Applications of Schiff bases, New York: Marcell Dekker, 1969.

37. S. Patai $(E d$.), The Chemistry of the Carbon-Nitrogen Double Bond, London: J. Wiley \& Sons, 1970.

38. C. M. Jamkhandi and J.I. Disouza, Int. J. Pharm. Pharma. Sci., 2013, 5, 249. 